\title{
PENGETAHUAN, MOTIVASI DAN KEPATUHAN DIET PASIEN DM TIPE II DI WILAYAH KERJA PUSKESMAS KALIWUNGU KENDAL
}

\author{
Abdul Azis ${ }^{1}$, Siti Aminah ${ }^{2}$ \\ 1. Perawat Puskesmas Kaliwungu Kendal \\ 2. Dosen STIKES Muhammadiyah Kendal \\ E-mail:sitiaminah.maulana@gmail.com
}

\begin{abstract}
Abstrak
Pengaturan diet pada pasien DM merupakan salah satu terapi yang penting dalam pengelolaan pasien DM. Pengetahuan pasien DM tentang penyakitnya merupakan sarana yang penting dalam membantu pasien DM patuh dalam menjalankan terapi diit, namun seringkali pengetahuan saja tidak cukup untuk membuat pasien patuh dalam menjalankan terapi. Salah satu faktor yang mempengaruhi kepatuhan adalah motivasi. Penelitian ini bertujuan untuk mengetahui hubunganan antara pengetahuan dan motivasi dengan kepatuhan diet pada pasien diabetes mellitus tipe II di wilayah kerja Puskesmas Kaliwungu Kendal. Penelitian ini menggunakan pendekatan deskriptif korelatif, dengan jumlah sampel 180 responden, pengambilan sampel dengan accidental sampling. Sebagian besar responden memiliki pengetahuan baik $(47,2 \%)$, sebagian besar responden mempunyai motivasi baik $(50,6 \%)$ dan sebagaian besar responden patuh dalam menjalankan $\operatorname{diet}(62,2 \%)$. Hasil penelitian ini menunjukkan ada hubungan antara pengetahuan dengan kepatuhan diet pada pasien diabetes mellitus tipe II dengan nilai $r$-value 0,760 dan pvalue $0,000(\mathrm{p}<0,05)$ dan ada hubungan antara motivasi dengan kepatuhan diet pada pasien diabetes mellitus tipe II dengan nilai $r$-value 0,819 dan $\mathrm{p}$-value $0,000((\mathrm{p}<0,05)$. Dari data tersebut dapat diketahui bahwa motivasi memiliki hubungan yang lebih signifikan dalam menentukan kepatuhan diet pasien, dengan demikian selain meningkatkan pengetahuan pasien perawat juga diharapkan meningkatkan motivasi pasien dalam mematuhi diet DM.
\end{abstract}

Kata Kunci: DM tipe II, Kepatuhan Diit, Motivasi, Pengetahuan.

\section{KNOWLEDGE, MOTIVATION, AND DIET ADHERENCE AMONG DM TYPE II PATIENTS IN KALIWUNGU KENDAL COMMUNITY HEALTH CENTRE WORKING AREA}

\begin{abstract}
Diet control in diabetic patients is one of the important therapies in the management of diabetic patients. Patient's knowledge about their disease is the important thing that can help diabetic patients obey their therapies. Unfortunately, knowledge alone is not enough to keep the patients adhere in the course of therapies. Motivation is one of the factors that can affeects patient's adherence. The aims of this study is to find out the relationship of knowledge and motivation with diet adherence among DM Type II patients in kaliwungu Kendal community health centre.This study used a descriptive correlative approach, with a sample of 180 respondents, sampling with accidental sampling. The result of this research shows that most of the respondents knowledge is good (47,2\%), have good motivation (50,6\%) and most of them are obedient in diet $(62,2 \%)$. The results of this study indicate a relationship between knowledge and dietary adherence in patients with type II diabetes mellitus with $r$-value 0,760 and p-value 0.000 ( $p<0.05)$, and motivation with dietary adherence in patients with type II diabetes mellitus with $r$-value 0,819 and $p$ value 0.000 ( $p<0.05)$. From this study we knows that motivation had more significant effectto determine patient's diet adherence, therefore aside from improving patient's knowledge the nurses also to be expected to improve patient's motivation in adhering to the diet.
\end{abstract}

Keywords: DM tipe II, adherence diet, motivation, knowledge 


\section{Pendahuluan}

Diabetes Melitus adalah salah satu jenis peyakit degenerative yang mengalami peningkatan setiap tahun di negara-negara seluruh dunia. Jumlah penderita diabetes di dunia menurut World Health Organization (WHO) pada tahun 2012 sebanyak 171.230.000. Berdasarkan data International Diabetes Federation (IDF, 2015) tingkat prevalensi global penderita DM pada tahun 2014 sebesar 8,3 \% dari keseluruhan penduduk di dunia dan mengalami peningkatan pada tahun 2015 menjadi10,7\% juta kasus. Indonesia merupakan negara urutan ke 5 di dunia dengan 7,6 juta orang penyandang DM dan IDF memprediksi adanya kenaikan jumlah penyandang DM di Indonesia dari 9,1juta pada tahun 2014 menjadi14,1 juta pada tahun 2035 (Perkeni, 2015). Jawa Tengah dengan 181.543 penderita menempati urutan ke4 dari dari seluruh propinsi di Indonesia. Menurut data dari Dinas Kesehatan Kabupaten Kendal tahun 2016 terdapat 18.699 pasien DM di wilayah Kendal.

Menurut Waspadji (2007) mengutip pendapat Joslin (1952) dari Medical Centre Institute, dalam penatalaksanaan diet diabetes mellitus ada 3 (tiga) yang harus diketahui dan dilaksanakan oleh pasien Diabetes mellitus, yaitu jumlah makanan, jenis makanan dan jadwal makanan. Kepatuhan diet merupakan suatu perubahan perilaku yang positif dan diharapkan, sehingga proses kesembuhan penyakit lebih cepat dan terkontrol. Pengaturan diet yang seumur hidup bagi penderita DM menjadi sesuatu yang sangat membosankan, jika dalam diri penderita tidak timbul pengertian dan kesadaran yang kuat dalam menjaga kesehatannya.

Pola makan yang tidak sehat karena sering mengonsumsi makanan sumber glukosa yang berlebihan akan meningkatkan kadar glukosa darah sehingga perlu dilakukan pengaturan diet diabetes mellitus. Dalam mengatur makanan diet diabetes mellitus tidak mudah karena menu yang dikonsumsi banyak yang dibatasi sehingga perlu adanya motivasi bagi pasien untuk mengontrol glukosa darah dengan mengatur pola makan (Suyono,2009).

Pengetahuan yang rendah dapat mempengaruhi persepsi pasien tentang penyakit diabetes mellitus (Sousa dan Zauseniewski, 2010). Pengetahuan atau kognitif merupakan domain yang sangat penting dalam membentuk tindakan seseorang (overtbehaviour). Berbagai penelitian menunjukan bahwa tingkat pengetahuan penderita DM masih rendah (Waspadji,2005). Pengetahuan pasien tentang DM merupakan sarana yang dapat membantu penderita menjalankan penanganan diabetes. 
Kepatuhan pasien terhadap prinsip gizi dan perencanaan makan merupakan salah satu kendala bagi pasien diabetes mellitus. Pasien diabetes banyak yang merasa tersiksa sehubungan dengan jenis dan jumlah makanan yang dianjurkan (Maulana,2009). Keberhasilan suatu pengobatan baik secara primer maupun sekunder, sangat dipengaruhi oleh kepatuhan penderita DM untuk menjaga kesehatannya. Bahkan akibat ketidakpatuhan dalam menjaga kesehatan, dapat berdampak pada komplikasi penyakit DM dan bisa berujung pada kematian (Saifunurmazah,2013).

\section{Tinjauan Teoritis}

Diabetes mellitus adalah penyakit metabolisme yang merupakan suatu kumpulan gejala yang timbul karena seseorang karena adanya peningkatan kadar glukosa darah diatas nilai normal (Smeltser, 2013).DM tipe II (NIDDM) disebakan karena obesitas yaitu menurunkan jumlah reseptor insulin dari sel target diseluruh tubuh sehingga insulin yang tersedia menjadi kurang efektif dalam meningkatkan efek metabolik. Tanda dan gejala DM menurut Wijaya dan Putri (2013) adalah banyak kencing (poliuria), banyak minum (polidipsi), banyak makan (polifagia), penurunan berat badan dan rasa lemah. Penatalaksanaan DM dapat dilakukan dengan cara pengaturan diet, mengkonsumsi obat hipoglikemik oral $(\mathrm{OHO})$, dan latihan fisik (Wijaya dan Putri, 2013).

Menurut Waspadji (2007), mengutip pendapat Joslin (1952) dari Medical Centre Institute, dalam penatalaksanaan diet diabetes mellitus ada 3 (tiga) J yang harus diketahui dan dilaksanakan oleh penderita DM diabetes mellitus, yaitu jumlah makanan, jenis makanan dan jadwal makanan. Jumlah makanan yang diberikan disesuaikan dengan status gizi penderita DM, bukan berdasarkan tinggi rendahnya gula darah. Jumlah kalori yang disarankan berkisar antara 1100-2900 KKal.(Waspadji, 2007).

Penderita diabetes mellitus harus membiasakan diri untuk makan tepat pada waktu yang telah ditentukan.Penderita diabetes mellitus makan sesuai jadwal, yaitu 3 kali makan utama, 3 kali makan selingan dengan interval waktu 3 jam. Ini dimaksudkan agar terjadi perubahan pada kandungan glukosa darah penderita DM, sehingga diharapkan dengan perbandingan jumlah makanan dan jadwal yang tepat maka kadar glukosa darah akan tetap stabil dan penderita DM tidak merasa lemas akibat kekurangan zat gizi. Jadwal makan standar yang digunakan oleh penderita DM (Waspadji, 2007) 


\section{Metode Penelitian}

Jenis penelitianyang dilakukan adalah penelitian deskriptif korelatif dengan pendekatan cross sectional. Sampel dalam penelitian ini sebanyak 180 responden dengan teknik accidental sampling. Variabel dalam penelitian adalah pengetahuan dan motivasi sebagai variable independent (bebas) dan kepatuhan diet pada pasien diabetes mellitus tipe II sebagai variable dependent (terikat).

Instrumen yang digunakan dalam penelitian ini terdiri dari kuesioner pengetahuan terdiri dari 18 pertanyaan, kuesioner motivasi. Menggunakan kuesioner terdiri dari 10 pertanyaan dan kuesioner kepatuhan diet terdiri dari 14 pertanyaan. Analisis dalam penelitian menggunakanan alisis univariat dan bivariat. Analisis univariatini hanya menghasilkan distribusi frekuensi dan persentase dari tiap variabel, sedangkan analisis bivariat dilakukan terhadap dua variable yang diduga saling berhubungan atau berkorelasi. Uji statistic yang digunakan dalam penelitian adalah uji ChiSquare (Chi kuadrat).

\section{Hasil Penelitian}

1. Analisa Bivariat

a. Hubungan Pengetahuan dengan kepatuhan diet pada pasien diabetes mellitus tipe II diwilayah kerja puskesmas Kaliwungu Kendal

Tabel 1

Hubungan Pengetahuan dengan Kepatuhan Diet

Pada Pasien Diabetes Mellitus tipe II

Di Wilayah Kerja Puskesmas Kaliwungu Kendal Tahun 2017

\begin{tabular}{|c|c|c|c|c|c|c|c|c|}
\hline \multirow{3}{*}{ Pengetahuan } & \multicolumn{4}{|c|}{ Kepatuhan diet } & \multicolumn{2}{|c|}{ Total } & \multirow[t]{3}{*}{ P value } & \multirow[t]{3}{*}{ r-value } \\
\hline & \multicolumn{2}{|c|}{ Patuh } & \multicolumn{2}{|c|}{ Tidak patuh } & & & & \\
\hline & $\mathrm{f}$ & $\%$ & $\mathrm{f}$ & $\%$ & $\mathrm{f}$ & $\%$ & & \\
\hline Baik & 83 & 46,1 & 2 & 1,1 & 85 & 47,2 & & \\
\hline Cukup & 27 & 15,0 & 29 & 16,1 & 56 & 31,1 & 0,000 & 0,760 \\
\hline Kurang & 2 & 1,1 & 37 & 20,6 & 39 & 21,7 & & \\
\hline Total & 112 & 62,2 & 68 & 37,8 & 180 & 100 & & \\
\hline
\end{tabular}

b. Hubungan motivasi dengan kepatuhan diet pada pasien diabetes mellitus tipe II di wilayah kerja Puskesmas Kaliwungu Kendal

Tabel 2

Hubungan Motivasi diet Diabetes Mellitus tipe II

dengan Kepatuhan Diet Pada Pasien Diabetes Mellitus tipe II

Di Wilayah Kerja Puskesmas Kaliwungu Kendal

Tahun 2017

Motivasi

Kepatuhan diet

Total

P value

r-value 


\begin{tabular}{lcccccccc}
\hline \multicolumn{7}{c}{ Patuh } & \multicolumn{7}{c}{ Tidak patuh } & & & & \\
& $\mathrm{f}$ & $\%$ & $\mathrm{f}$ & $\%$ & $\mathrm{f}$ & $\%$ & & \\
\hline Baik & 90 & 50,0 & 1 & 0,6 & 91 & 50,6 & & \\
Cukup & 21 & 11,7 & 27 & 15,0 & 48 & 26,7 & 0,000 & 0,819 \\
Kurang & 1 & 0,6 & 40 & 22,2 & 41 & 22,8 & & \\
\hline Total & $\mathbf{1 1 2}$ & $\mathbf{6 2 , 2}$ & $\mathbf{6 8}$ & $\mathbf{3 7 , 8}$ & $\mathbf{1 8 0}$ & $\mathbf{1 0 0}$ & & \\
\hline
\end{tabular}

c. Hubungan pengetahuan dan motivasi dengan kepatuhan diet pada pasien diabetes mellitus tipe II di wilayah kerja Puskesmas Kaliwungu Kendal

Tabel 3

Hubungan Tingkat Pengetahuan dan Motivasi Diit Diabetes Mellitus Tipe II dengan Kepatuhan Diet Pada Pasien Diabetes Mellitus tipe II

Di Wilayah Kerja Puskesmas Kaliwungu Kendal

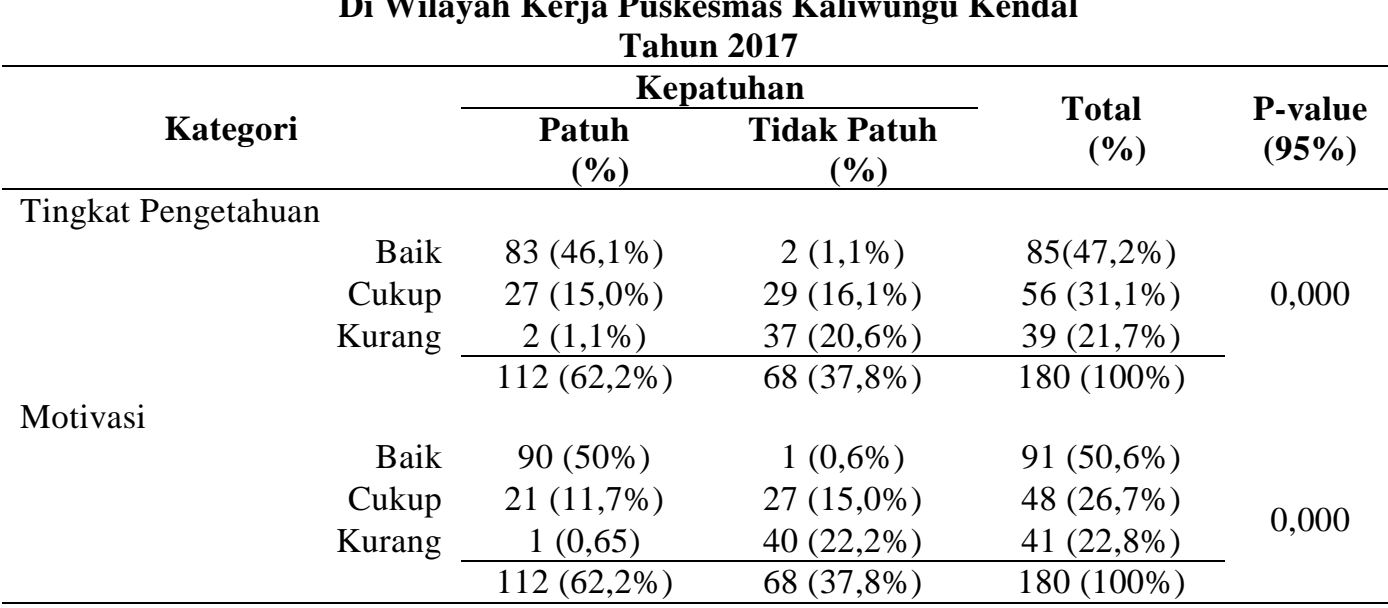

Hasil penghitung menggunakan chi - square didapatkan nilai p value 0,000 $(\mathrm{P}<0,05)$ yang menunjukkan ada hubungan motivasi dengan kepatuhan diet pada pasien diabetes mellitus tipe II di wilayah kerja Puskesmas Kaliwungu Kendal.

\section{Pembahasan}

1. Pengetahuan tentang diet pada pasiendiabetes mellitustipeII di wilayah kerja Puskesmas Kaliwungu Kendal

Hasil penelitian menunjukkan sebagian besar responden $(47,2 \%)$ memiliki pengetahuan yang baik tentang diet pada pasien diabetes mellitus tipe II. Pengetahuan diperlukan sebagai dukungan dalam menimbulkan rasa percaya diri maupun sikap dan perilaku setiap hari (Notoatmodjo, 2012).Pengetahuan adalah kesan didalam pikiran manusia sebagai hasil penggunaan panca inderanya yang diketahui berdasarkan pengalaman yang didapatkan oleh setiap manusia (Mubarak, 2011). Pengetahuan responden didapat dari pengalaman, penyuluhan kesehatan, informasi dari petugas kesehatan. 
Pengetahuan yang baik dari responden dikarenakan kemungkinan responden sudah mendapatkan pendidikankesehatan dari petugas puskesmas dan mengidap penyakit DM dalam jangka waktu yang lama sehingga responden telah mencari informasi tentang pengetahuan diet pada pasien DM. Hasil penelitian ini sejalan dengan penelitian yang dilakukan oleh Cahyati(2015) tentang hubungan tingkat pengetahuan diet diabetes mellitus dengan kepatuhan diet pada penderita diabetes mellitus tipe II di dusun Karang Tengah Yogyakarta mayoritas responden memiliki tingkat pengetahuan diet baik tentang diabetes mellitus.

2. Motivasi pada pasien diabetes mellitus tipe II di wilayah kerja Puskesmas Kaliwungu Kendal

Hasil penelitian menunjukkan sebagian besar responden $(50,6 \%)$ memilki motivasi baik. Motivasi adalah keadaan dalam pribadi seseorang yang mendorong keinginan individu untuk melakukan kegiatan tertentu guna mencapai suatu tujuan (Marquis \& Huston, 2010). Motivasi merupakan salah satu factor yang memberikan pengaruh terhadap kepatuhan responden. Motivasi yang tinggi dapat meningkatkan kepatuhan diet responden DM tipe II dalam perawatan diri (Da Silva,2013). Motivasiyang baik dari responden kemungkinan disebabkan oleh adanya keinginan yang kuat dari dalam diri responden untuk sembuh dan terhindar dari berbagai komplikasi yang diakibatkan oleh DM.

3. Kepatuhan diet pada pasien diabetes mellitus tipe II diwilayah kerja Puskesmas Kaliwungu Kendal

Hasil penelitian menunjukkan sebagian besar responden patuh dalam menjalani diet diabetes mellitus tipe II. Kepatuhan adalah perubahan sikap dan tingkah laku seseorang untuk mengikuti permintaan atau perintah orang lain (Hartono, 2010). Kepatuhan secara umum didefinisikan sebagai tingkatan perilaku seseorang yang mendapatkan pengobatan, mengikuti diet dan melaksanakan gaya hidup sesuai dengan rekomendasi pemberi pelayanan kesehatan (WHO, 2013). Salah satu wujud kepatuhan responden adalah dengan cara mengikuti anjuran diet yang disarankan oleh ahli gizi.

Banyaknya responden yang patuh menjalankan diet karena motivasi yang ada pada diri responden tersebut untuk mematuhi diet yang berikan. Motivasi ini muncul karena responden yakin apabila dia tidak mematuhi aturan diet maka hal ini akan dapat membuat kadar gula darahnya naik ataupun menurun, sehingga agar gula darahnya tetap stabil maka responden mau tidak mau harus mematuhi aturan diet. 
4. Hubungan pengetahuan dengan kepatuhan diet pada pasien diabetes mellitus tipe II di wilayah kerja puskesmas Kaliwungu Kendal

Hasil penelitian ini menunjukkan sebagian besar responden yang memilki pengetahuan baik patuh dalam menjalankan diet sebanyak(46,1\%). Hasil penghitungan menggunakan pearson product moment didapatkan r-value 0,760 dengan p-value 0,000, dengan demikian dapat disimpulkan bahwa ada hubungan antara pengetahuan dengan kepatuhan diet pada pasien DM tipe II di wilayah kerja Puskesmas Kaliwungu Kendal. Pengetahuan merupakan domain yang sangat penting untuk terbentuknya tindakan seseorang karena dengan pengetahuan yang baik dapat menciptakan kepatuhan yang baik (Notoatmodjo, 2012).

Responden yang memiliki pengetahuan yang baik lebih cendrung patuh, hal ini terjadi karena pengetahuan yang dimiliki responden mengenai diet DM akan menimbulkan kesadaran bagi responden dan akhirnya akan menyebabkan berperilaku sesuai dengan apa yang mereka ketahui. Oleh karena itu, pada penelitian ini responden dengan pengetahuan baik patuh dalam menjalankan segala anjuran diet dari dokter/tenaga kesehatan mereka mengetahui bahwa apabila mereka tidak patuh dalam menjalankan diet maka akibatnya mereka akan lebih mudah terkena komplikasi DM.

5. Hubungan motivasi dengan kepatuhan diet pada responden diabetes mellitus tipeII di wilayah kerja Puskesmas Kaliwungu Kendal

Hasil penelitian menunjukkan sebagian besar responden yang memiliki motivasi baik patuh dalam menjalankan diet (50,0\%). Hasil penghitungan menggunakan pearson product moment didapatkan $r$-value 0,819 dengan p-value 0,000, dengan demikian dapat disimpulkan bahwa ada hubungan antara motivasi dengan kepatuhan diet pada pasien DM tipe II di wilayah kerja Puskesmas Kaliwungu Kendal. Motivasi adalah segala sesuatu yang mendorong seseorang untuk melakukan sesuatu (Winardi, 2010). Banyaknya responden yang memiliki motivasi baik dan patuh dalam menjalankan diet kemungkinan dikarenakan mereka terdorong untuk patuh, karena mereka mengetahui konsekwensi akibat ketidakpatuhan tersebut dapat membuat gula darah meraka tidak stabil, menyulitkan penyembuhan dan meningkatkan resiko komplikasi sehingga adanya keinginan untuk terhindar dari hal-hal negatif tersebut menyebabkan mereka patuh dalam menjalankan diet DM.

\section{Kesimpulan}

Sebagian besar responden memiliki pengetahuan baik $(47,2 \%)$, sebagian besar responden 
memiliki motivasi baik (50,6\%), dan sebagian besar responden patuh dalam menjalankan diet DM (46,1\%). Ada hubungan antara pengetahuan dengan kepatuhan dalam menjalankan diet DM Tipe II dengan $r$-value 0,760 dan p-value 0,000. Ada hubungan antara motivasi dengan kepatuhan dalam menjalankan diet DM tipe II dengan $r$-value 0,819 dan p-value 0,000. Dari hasil tersebut dapat disimpulkan bahwa pengetahuan dan motivasi mempengaruhi kepatuhan pasien DM tipe II dalam menjalankan diet DM, namun motivasi lebih signifikan dalam menentukan kepatuhan pasien DM tipe II dalam menjalankan diet DM.

\section{Saran}

Bardasarkan hasil dari penelitian ini maka diharapkan Dinas Kesehatan melalui Puskesmas memberikan lebih banyak informasi tentang diet DM pada pasien DM dan juga mempertahankan dan meningkatkan motivasi pasien dengan melibatkan keluarga dalam meningkatkan motivasi dan kepatuhan pasien dalam melaksanakan diet DM. Untuk penelitian selanjutnya diharapkan dapat menggali faktor-faktor yang dapat mempengaruhi motivasi pasien DM dalam menjalankan diet DM.

\section{Daftar Pustaka}

Perkeni. (2015). Konsensus Pengelolaan diabetes melitus tipe2 di indonesia

Smeltser, S. C. (2013). Buku Ajar Keperawatan Medikal Bedah. Jakarta. EGC

Sousa \& Zauseniewski. (2010). Toward a theory of diabetes self-caremanagement. Journal of Theory Construction \& Testing; Diunduh dari http://proquest.umi.com/pqdweb

Maulana. (2009). Promosi Kesehatan.Jakarta: EGC

Saifunurmazah. (2013). Kepatuhan Penderita Diabetes Mellitus Dalam.Menjalani Terapi Olahraga Dan Diet. Universitas Negeri Semarang .Skripsi

Winardi.(2010). Motivasi \& Pemotivasian dalam Manajemen.Jakarta : PT. RajaGrafindo Persada

Notoatmodjo, S. (2012).Promosi Kesehatan Teori dan Aplikasi. Jakarta: PT. Rineka Cipta

Hartono. (2010). Terapi Gizi dan Diet Rumah Sakit. Jakarta: EGC

Safitri (2013). Kepatuhan Penderita Diabetes Mellitus Tipe II Ditinjau Dari Locus Of Control.

Wade dan Travis (2008). Psikologi. Edisi Kesembilan. Jilid 2. (terjemahan : Padang Mursalin dan Dinastuti). Jakarta : Erlangga 